\title{
Forecasting interregional commodity flows using artificial neural networks: an evaluation
}

\section{H. Murat Celik}

To cite this article: $\mathrm{H}$. Murat Celik (2004) Forecasting interregional commodity flows using artificial neural networks: an evaluation, Transportation Planning and Technology, 27:6, 449-467, DOI: $10.1080 / 0308106042000293499$

To link to this article: http://dx.doi.org/10.1080/0308106042000293499

曲 Published online: 01 Feb 2007.

Submit your article to this journal $\sqsubset$

山 Article views: 64

Q View related articles $\sqsubset$

4 Citing articles: 3 View citing articles $\square$ 


\title{
FORECASTING INTERREGIONAL COMMODITY FLOWS USING ARTIFICIAL NEURAL NETWORKS: AN EVALUATION
}

\author{
H. MURAT CELIK \\ Department of Civil Engineering, Izmir Institute of Technology, Izmir, Turkey \\ 35437
}

(Received 3 February 2004; Revised 2 September 2004; In final form 9 September 2004)

Previous studies have concluded that the use of artificial neural networks (ANNs) is a promising new technique for modelling freight distribution, supporting the findings of other studies in the area of spatial interaction modelling. However, the forecasting performance of ANNs is still under investigation. This study tests the predictive performance of the ANN Model with respect to a Box-Cox spatial interaction model. It is concluded that the Box-Cox model outperforms ANN in forecasting interregional commodity flows even if ANN had proven calibration superiority in comparison to conventional gravity type models.

Keywords: Artificial neural networks; Spatial interaction models; Commodity flows; Freight transportation

\section{INTRODUCTION}

Applications of artificial neural networks (ANNs) in spatial interaction modelling include passenger flows [1,2], commodity flows [3,4], telecommunication flows [5] and migration [4]. Each of these studies concluded that ANNs have proven significant superiority over conventional gravity model formulations in replicating base-year data. This

*Corresponding author. E-mail: muratcelik@iyte.edu.tr 
superiority has implied that ANNs could be a very promising technique for the prediction of spatial interactions.

Fisher and Gopal [5] modelled interregional telecommunication flows using 1991 data for Austria. The ANN employed was based on a one-input, two-hidden layer feed-forward, back-propagation architecture. Using a gravity model with three conventional variables as a benchmark, they compared the performances of the ANNs with different initial conditions. Depending on the number of neurons in the hidden layers, the performances of the ANNs were either comparable or superior to that of the gravity model.

Black [4] obtained a similar result. He tested whether basic neural network models could be developed using the same inputs as existing methods and perform as well as or better than those methods. In this sense, an ANN model was calibrated using conventional gravity model variables both for 1977 US commodity flows data and 1965-1970 US migration data separately. In both cases, the ANN model results outperformed those of the benchmark gravity models.

In an earlier study, Celik [3] fed a theoretically relevant variable set into a feed-forward back-propagation ANN model for 15 commodity groups using the 1993 US Commodity Flow Survey. The performances of specified ANN models were compared with a benchmark Box-Cox model with the same variables set. For every commodity group, the results of the ANN model outperformed that of the BoxCox model in terms of replicating observed base year data.

None of the studies discussed above reported on the predictive performance of their ANN models. However, Mozolin et al. [2] focused on the predictive ability of ANN Model. They calibrated a multilayer perceptron neural network and a doubly constrained gravity model as a benchmark using the 1980 Atlanta Metropolitan Area work trips data. In the calibration phase, the performance of ANN was found superior to that of gravity model. However, when the calibrated models were used to replicate 1990 data, the gravity model performed better. Their findings concluded that neural networks do not provide an appropriate modelling approach to forecasting trip distribution over a planning horizon for which distribution predictors (number of workers, number of residents, commuting distance) are well beyond their base-year domain definition; in addition, ANNs do not provide a good temporal transferability. This result sounds rather disappointing. Obviously, the hypothesis that an ANN is not appropriate for trip distribution forecasting needs more empirical and analytical research.

The aim of this paper is to evaluate empirically the predictive 
performance of ANN models in the area of commodity flows with respect to an existing benchmark model. While earlier studies in this area of research focused on the training and validation of ANNs, this study focuses on the predictive performance of ANNs for different commodity groups. For this purpose, the ANN and Box-Cox models, validated by Celik [3] using the 1993 US commodity flows data for 15 commodity groups, are tested against the 1997 US commodity flows data in order to check the predictive performance of the ANN models.

The next section of the paper presents an outline of commodity flows as a form of spatial interaction. A basic discussion about ANNs is included in the third section. The fourth section of the paper explains the data and variable sets used in the study. Results are discussed in section five. The final section is devoted to concluding remarks. Some illustrations of the results are provided in the Appendix.

\section{COMMODITY FLOWS AS SPATIAL INTERACTION}

In a broad sense, spatial interaction has been defined by Fotheringham and O'Kelly [6] as movement or communication over space that results from a decision process. They conclude that the term encompasses such diverse behaviour as migration, shopping, the choice of healthcare services, travel-to-work, recreation, the movement of goods, telephone calls, the choice of a university by students, airline passenger traffic, even attendance events such as conferences, theatres and football matches.

Commodity flows, among other types of spatial interaction, occupy a place at the conjunction of many different disciplines such as transportation planning, macro-economics, regional science, city planning and geography, since it is one of the most obvious reflections of an economy. Furthermore, the data required for analysis of commodity flows is costlier and more difficult to obtain since the facilitation of this type of spatial interaction is achieved by many different economic agents. The relatively few published studies using commodity flows and the small number of databases available confirm this fact. For this reason, a robust commodity flows prediction technique could provide savings in the costs associated with building and updating databases.

Techniques used for modelling commodity flows include general equilibrium models (input-output models), optimization models and gravity models. General equilibrium models require extensive data, and may be prohibitively expensive to build. Optimization models may 
produce distorted results due to back-hauling, especially when there is an insufficient level of commodity disaggregation [3,7]. For these reasons, a gravity model is frequently used for the spatial interaction modelling of commodity flows.

As in other areas, ANNs have demonstrated a good ability to model commodity flows $[3,4]$. However, studies in this area were limited to the calibration results, and their predictive performance was only reported by Mozolin et al. [2] in modelling spatial interaction of work-trips.

This paper uses the Box-Cox spatial interaction model specified by Celik and Guldmann [7] as being a benchmark, and the ANN model specified by Celik [3] for the prediction of the 1997 US Commodity Flows Data. These models are estimated using the 1993 US Commodity Flow Survey Data. In these models, flows are considered as a function of three groups of theoretically relevant variables: variables characterizing origins, destinations and geography. The total number of variables is 16 . In mathematical terms this may be represented as:

$$
F_{i j}=a_{i} \text { (origin variables) } f_{i j} \text { (geographical variables) } b_{j} \text { (destination }
$$
variables)

The functional form is a flexible Box-Cox model as follows:

$\frac{Y^{\theta}-1}{\theta}=a_{0}+a_{1} X_{1}+a_{2} \frac{X_{2}^{\lambda}-1}{\lambda}+\ldots+a_{n} \frac{X_{n}^{\lambda}-1}{\lambda}+\varepsilon$

where all the variables, except for dummy variables, are transformed in this specification. $\theta, \lambda$ and $a_{n}$ are the parameters to be determined endogenously. The Box-Cox transformation in Eq. (2) is continuous at $\lambda=0$ because $X^{\lambda}$ tends to $\operatorname{Ln} X$ when $\lambda->0$. Thus, with a maximum likelihood estimator, the Box-Cox formulation determines a best fitting functional form endogenously in any range between linear and log-linear functional forms.

\section{ARTIFICIAL NEURAL NETWORKS}

An ANN is an abstract interpretation of the human brain and its nervous system, and an imitator of human learning and cognitive processes. Inputs are fed into artificial neurons giving different weights to imitate the biological synaptic strengths in a natural neuron. Neurons are organized as layers, called 'hidden layers'. Depending on the network architecture chosen, the number of hidden layers may vary. 
Neurons evaluate the weighted sums of inputs, which is the product of input and weight vectors, and this product is called a net in the ANN literature. In mathematical terms:

$$
n e t=x^{*} w
$$

where $\boldsymbol{x}$ is an input vector and $\boldsymbol{w}$ is a weight matrix. The evaluation of the net in a neuron is achieved by a transfer function to produce an output:

$$
y=f(n e t)
$$

This output is the network output if the architecture includes only one hidden layer. In multilayer architectures, however, the estimated output is the input to the next hidden layer. The system's output is compared with target (observed) values and an error term is estimated:

$$
E=\left(\frac{1}{2}\right) \sum_{j}\left(t_{j}-y_{j}\right)^{2}
$$

where $t_{j}$ is the target and $y_{j}$ are output values. In order to minimize the error term, the weights are adjusted iteratively until no convergence occurs. In back-propagation neural networks, this adjustment is undertaken from output vector to input vector through hidden layers. This process is referred to as the learning procedure, and it is done by adding a small fraction of weights at each iteration:

$$
w^{n+1}=w^{n}+\Delta w \mathrm{n}
$$

where

$$
\Delta w^{n}=-\delta\left(\frac{\partial E}{\partial w}\right),
$$

and $\delta$ being a positive constant called the learning rate.

This brief description of neural networks is a basic explanation of the feed-forward back-propagation architecture. Of course, there are many other architectures and specifications available [8,9].

As can be seen in Fig. 1, a two hidden layer, feed-forward backpropagation architecture is employed in this study [3]. The number of neurons in the first hidden layer is as many as the input variables (namely 16) while the second hidden layer contains only one neuron. The activation or transfer function used in both layers is a non-linear sigmoid function:

$$
y=1 /[1+\exp (n e t)]
$$




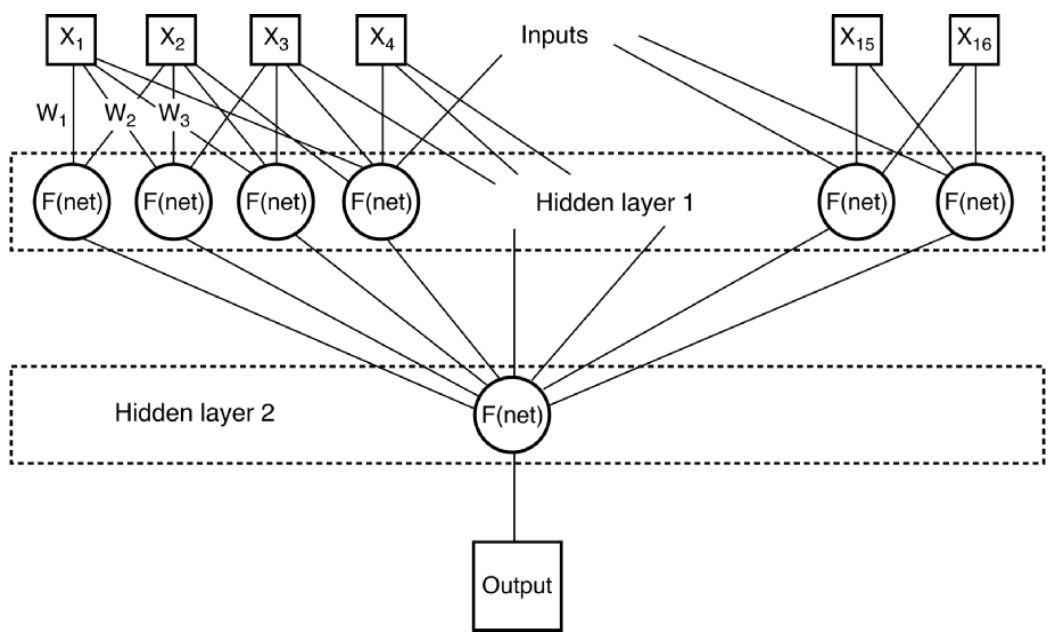

FIGURE 1 Specification of the neural network architecture

\section{VARIABLES AND DATA}

\subsection{Variables}

The dependent variable is the flow of commodities measured in US\$ millions. The 16 independent variables are grouped into three broad categories in this study: origin variables, destination variables and geographical variables. Origin variables include: sectoral employment, sectoral value-added by product group, wholesale employment, average plant size by product group, total population and personal income per capita by origin. Destination variables include: total manufacturing employment, personal income per capita, total population and wholesale employment by destination. These variables are used as proxies for demand and supply conditions at origins and destinations. There are six additional variables to encompass the geographical features of spatial interaction, which are the 48 continental states of the USA, excluding Washington DC, shown in Fig. 2. These include: the average distance of all commodities shipped, competing destinations and intervening opportunities variables to capture the effects of geographical configuration of origins and destinations; the remaining variables are dummies - if a destination has a customs district, if an 


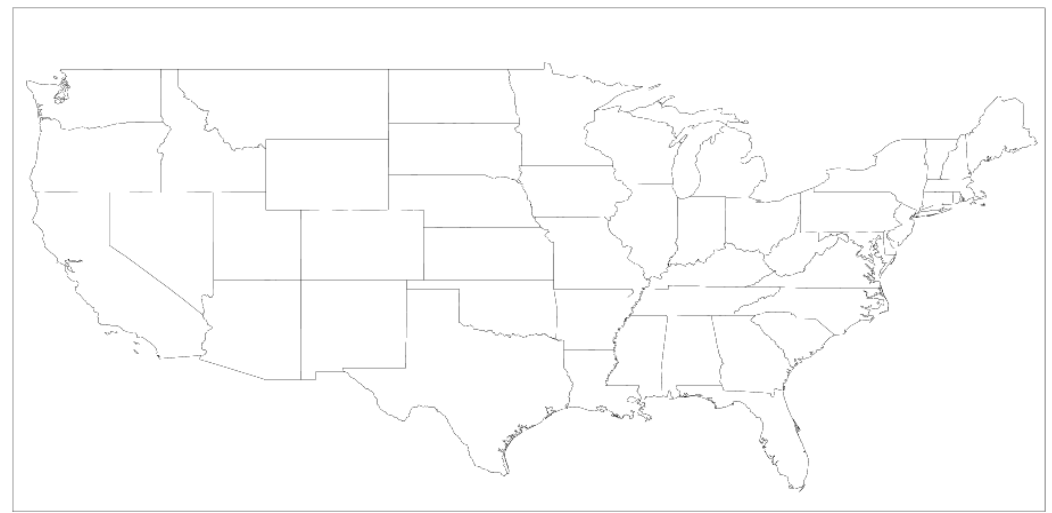

FIGURE 2 Interaction space of commodity flows: Continental USA

origin has a customs district and if trading states share a common physical border.

\subsection{Data Sources and Processing}

Dependent variables for the years 1993 and 1997 are drawn from the respective US Commodity Flow Surveys (CFS). File 9 in the 1993 CFS and File 14 in the 1997 CFS include the values of commodity out-shipments from each origin state to every other state for each commodity group at the two-digit level. The 1993 CFS used the Standard Transportation Commodity Classification (STCC) which was changed to the Standard Classification of Transported Goods (SCTG) for the 1997 CFS. In order to provide comparability between the two years, the 1997 SCTG classification system was converted into the 1993 STCC classification system. After analysing and comparing both systems at the three- and four-digit levels, the conversion was undertaken at the two-digit level according to the matching presented in Table I.

Since SCTG is a more detailed system, in general one STCC commodity group includes more than one SCTG commodity group, and this makes conversion easy and somewhat dependable. The only exception is SCTG group 30, which includes STCC groups 22, 23 and 31. This group was recoded as group 75: textile mill, apparel and leather products. When regrouping SCTG-defined flows in 1997 (e.g. SCTG groups 20, 21, 22 and 23 were summed for any O-D pair to obtain STCC group 28), if one SCTG flow was missing for an O-D 
TABLE I Matching of SCTG and STCC groups

\begin{tabular}{|c|c|c|c|}
\hline Sctg & Description & Stcc & Description \\
\hline 4 & Products of animal origin & 20 & Food or kindred products \\
\hline 5 & Meat, fish, seafood, and preparations & 20 & Food or kindred products \\
\hline 6 & Milled grain and bakery products & 20 & Food or kindred products \\
\hline 7 & Prepared foodstuf, nec and fats and oils & 20 & Food or kindred products \\
\hline 8 & Alcholic beverages & 20 & Food or kindred products \\
\hline 10 & Monumental or building stone & 32 & Clay, concrete glass, or stone products \\
\hline 11 & Natural sands & 14 & Nonmetallic minerals \\
\hline 12 & gravel and crushed stone & 14 & Nonmetallic minerals \\
\hline 13 & Non-metallic minerals nec & 14 & Nonmetallic minerals \\
\hline 14 & Metallic ores & 10 & Metallic ores \\
\hline 15 & Coal & 11 & Coal \\
\hline 17 & Gasoline and aviation products & 13 & Crude petroleum, natural gas, or gasoline \\
\hline 18 & Fuel oils & 13 & Crude petroleum, natural gas, or gasoline \\
\hline 20 & basic chemicals & 28 & Chemicals or allied products \\
\hline 21 & pharmaceutical products & 28 & Chemicals or allied products \\
\hline 22 & Fertilizers and fertilizer materials & 28 & Chemicals or allied products \\
\hline 23 & Chemical products and preparations & 28 & Chemicals or allied products \\
\hline 24 & Plastics and rubber & 30 & Rubber of misc. plastic products \\
\hline 25 & Logs and other wood in the rough & 24 & $\begin{array}{l}\text { Lumber or wood products, excluding } \\
\text { furniture }\end{array}$ \\
\hline 26 & Wood products & 24 & $\begin{array}{l}\text { Lumber or wood products, excluding } \\
\text { furniture }\end{array}$ \\
\hline 27 & Pulp, newsprint, paper, and paperboard & 26 & Pulp, paper, or allied products \\
\hline 28 & paper and paperboard articles & 26 & Pulp, paper, or allied products \\
\hline 29 & Printed products & 27 & Printed matter \\
\hline 30 & Textiles, leather, and articles & 75 & $\begin{array}{l}\text { Textile mill products, apparel, and leather } \\
\text { products }\end{array}$ \\
\hline 31 & Nonmetallic mineral products & 32 & Clay, concrete glass, or stone products \\
\hline 32 & Base metal in primary finished basic form & 33 & Primary metal products \\
\hline 33 & articles of base metal & 34 & Fabricated metal products \\
\hline 34 & Machinery & 35 & Machinery, excluding electrical \\
\hline 35 & Electronic and other electrical equipment & 36 & Electrical machinery, equipment, or supply \\
\hline 36 & Vehicles & 37 & Transport equipment \\
\hline 37 & transportation equipment, nec & 37 & Transport equipment \\
\hline 38 & Precision instruments and apparatus & 38 & Instrument, photographic, optical goods \\
\hline 39 & Furniture, mattresses and matress supports & 25 & Furniture of fixture \\
\hline 40 & Miscellaneous manufactured pfoducts & 39 & Miscellaneous manufactured pfoducts \\
\hline
\end{tabular}

pair, then this pair was discarded. This process, however, inevitably reduces the size of the 1997 database. The Commodity Classification Code definitions used in this study are presented in Table II.

Since an ANN can only estimate parameters for existing O-D pairs, the analysis is needed to be done for the same O-D pairs in both years so that a spatial comparison is possible. For this reason, the O-D pairs that exist in both years' data are included. Both years' flows are 
FORECASTING INTERREGIONAL COMMODITY FLOWS USING ANNS 457

TABLE II Commodity group codes and definitions

\begin{tabular}{ll}
\hline Codes & \multicolumn{1}{c}{ Definitions } \\
\hline 20 & Food and kindred products \\
24 & Lumber or wood products \\
25 & Furniture or fixture products \\
26 & Pulp, paper or allied products \\
28 & Chemicals or allied products \\
30 & Rubber or plastics products \\
32 & Clay, concrete, glass or stone products \\
33 & Primary metal products \\
34 & Fabricated metal products \\
35 & Machinery, excluding electrical, products \\
36 & Electrical machinery products \\
37 & Transportation equipment \\
38 & Precision instruments \\
39 & Miscellaneous freight shipment \\
75 & Textile, apparel and leather products \\
\hline
\end{tabular}

reported in current monetary values. For this reason, 1997 flow values are deflated to 1993 prices using the GDP implicit price deflator provided by the US Department of Commerce's Bureau of Economic Analysis' National Economic Accounts Database. Descriptive statistics for both years' flows are presented in Table III.

A visual inspection of Table III reveals that there are no significant distortions between the two years' means, standard deviations or maximum values, except for a few commodity groups. A paired $t$-test

TABLE III Descriptive statistics of flow data

\begin{tabular}{lrrrrrrrrr}
\hline & \multicolumn{4}{c}{1993 (million US\$) } & \multicolumn{3}{c}{1997 (million US\$) } \\
$c c$ & \multicolumn{1}{c}{$n$} & mean & st. dev. & min. & max. & mean & st. dev. & min. & max. \\
\hline 20 & 238 & 313 & 675 & 0 & 4073 & 243 & 510 & 0 & 3284 \\
24 & 694 & 32 & 114 & 0 & 1908 & 34 & 115 & 0 & 1803 \\
25 & 922 & 35 & 63 & 0 & 429 & 40 & 71 & 0 & 558 \\
26 & 617 & 117 & 192 & 0 & 1563 & 116 & 186 & 0 & 1318 \\
28 & 165 & 285 & 547 & 0 & 3356 & 270 & 464 & 0 & 3428 \\
30 & 1051 & 85 & 124 & 0 & 969 & 128 & 193 & 0 & 1679 \\
32 & 720 & 21 & 40 & 0 & 311 & 21 & 42 & 0 & 364 \\
33 & 938 & 124 & 256 & 0 & 3060 & 139 & 309 & 0 & 4625 \\
34 & 1035 & 114 & 181 & 0 & 1766 & 97 & 171 & 0 & 1760 \\
35 & 1015 & 202 & 348 & 0 & 3721 & 182 & 306 & 0 & 4306 \\
36 & 1030 & 210 & 400 & 0 & 5606 & 373 & 867 & 0 & 12606 \\
37 & 296 & 484 & 1006 & 0 & 7800 & 500 & 1168 & 0 & 11197 \\
38 & 701 & 97 & 195 & 0 & 1999 & 88 & 160 & 0 & 1521 \\
39 & 1079 & 75 & 144 & 0 & 2062 & 167 & 268 & 0 & 2189 \\
75 & 367 & 333 & 573 & 0 & 3444 & 250 & 426 & 0 & 3159 \\
\hline
\end{tabular}


for both years' observation mean values is performed for each commodity group to check the hypothesis that 'there is no significant difference between two years' mean values'. The statistic obtained was -0.53 which is well below the one-tailed critical $t$ value, confirming the hypothesis. Thus, we may conclude that the regrouping of commodity classes has produced a compatible grouping.

For independent or input variables, three main databases have been used. Origin sectoral employment, origin wholesale employment, destination manufacturing employment and destination wholesale employment were obtained from the 1993 and 1997 County Business Patterns (CBP) Databases respectively. The origin average establishment size variables were estimated by dividing the origin sectoral employment by the number of establishments in that sector. The numbers of establishments were also drawn from the CBP database. The valueadded variables were drawn from the 1992 and 1997 Census of Manufactures. The state personal income per capita variables and the state population variables were drawn from the Annual State Personal Income database of the Bureau of Economic Analysis. The distance variable was derived directly from the 1993 and 1997 CFSs as average hauled distance. File 9 in the 1993 CFS and File 14 in the 1997 CFS have both tonnage and ton-mile values for each commodity group. Dividing ton-miles by ton values, the average hauled distance for each commodity group between each O-D pair was estimated. The competing destinations variable and the intervening opportunities variable were estimated using distance and total employment data.

\section{RESULTS}

The models used for prediction were estimated, calibrated and reported in earlier studies [3,7]. The estimated Box-Cox and the trained ANN Models with the 1993 CFS data were used to replicate the 1993 data with all 16 variables. The 'goodness of fit' statistics - the standardized root mean square error (SRMSE) and $R^{2}$ - for the calibrated models are reported in Table IV. According to both statistics, the ANN Model proved superior to the Box-Cox model for all 15 commodity groups. The $R^{2}$ values varied between 0.353 and 0.796 for the Box-Cox model while it was around 0.98 for all commodity groups for the ANN model. Furthermore, SRMSEs were well below unity for all commodities for the ANN model whereas it was only below unity for four commodity groups. On average, the ANN model obtained an $80 \%$ 
TABLE IV Calibration performance of the models

\begin{tabular}{lcccc}
\hline & \multicolumn{2}{c}{ Box-Cox } & \multicolumn{2}{c}{ ANN } \\
Codes & $R^{2}$ & SRMSE & $R^{2}$ & SRMSE \\
\hline 20 & 0.796 & 0.9275 & 0.987 & 0.2368 \\
24 & 0.593 & 1.7562 & 0.991 & 0.2593 \\
25 & 0.247 & 2.0090 & 0.987 & 0.2590 \\
26 & 0.779 & 0.9264 & 0.981 & 0.2705 \\
28 & 0.671 & 1.2338 & 0.979 & 0.3116 \\
30 & 0.776 & 0.8711 & 0.975 & 0.2898 \\
32 & 0.353 & 1.8045 & 0.983 & 0.2909 \\
33 & 0.778 & 1.2392 & 0.993 & 0.2261 \\
34 & 0.775 & 0.9453 & 0.983 & 0.2613 \\
35 & 0.665 & 1.1741 & 0.984 & 0.2591 \\
36 & 0.666 & 1.3194 & 0.989 & 0.2348 \\
37 & 0.544 & 1.7317 & 0.990 & 0.2595 \\
38 & 0.642 & 1.4950 & 0.990 & 0.2557 \\
39 & 0.589 & 1.5132 & 0.987 & 0.2716 \\
75 & 0.508 & 1.7330 & 0.999 & 0.0535 \\
\hline
\end{tabular}

error reduction for all commodity groups with respect to the Box-Cox model [3].

Examining the calibration of the models, it is possible to say that the ANN shows almost a perfect fit for replicating the observed commodity flow pattern, and this result seemed promising to forecast the interregional commodity flows. However, the findings of the present study do not support this initial expectation. As will be explained shortly, the Box-Cox model outperforms the ANN model for predicting the 1997 US interregional commodity flows.

For performance evaluation of spatial interaction models, a combination of three 'goodness of fit' statistics are recommended - information gain, SRMSE and $R^{2}[6]$. On the other hand, the ANN literature widely uses average relative variances (ARV) and SRMSE [10]. In this study, the ARV and SRMSE are also preferred for performance evaluation. ARV is defined as:

$$
A R V=\frac{\sum_{i}^{n}\left(y_{i}-\hat{y}_{i}\right)^{2}}{\sum_{i}^{n}\left(y_{i}-\bar{y}\right)^{2}}
$$

where $y_{i}$ denotes the observed values, $\hat{y}_{i}$ the predicted values, and $\bar{y}$ the mean of observed values. The statistics have a lower limit of zero indicating a perfect fit. Note that ARV is a normalized mean squared error and is independent of sample size. As Fischer et al. [10] have 
TABLE V Prediction performance of the models

\begin{tabular}{lllllllll}
\hline & \multicolumn{3}{c}{$A R V$} & & \multicolumn{4}{c}{ SRMSE } \\
Order & $c c$ & $B C M$ & $c c$ & $A N N$ & $c c$ & $B C M$ & $c c$ & $A N N$ \\
\hline 1 & 20 & 0.142 & 20 & 0.607 & 26 & 0.758 & 30 & 1.962 \\
2 & 24 & 0.195 & 26 & 0.623 & 28 & 0.904 & 39 & 2.087 \\
3 & 26 & 0.245 & 33 & 0.655 & 30 & 0.908 & 34 & 2.424 \\
4 & 38 & 0.311 & 28 & 0.762 & 35 & 0.988 & 25 & 2.473 \\
5 & 32 & 0.345 & 32 & 0.779 & 20 & 0.990 & 26 & 2.812 \\
6 & 28 & 0.367 & 38 & 0.838 & 34 & 1.038 & 33 & 2.952 \\
7 & 25 & 0.375 & 37 & 0.913 & 39 & 1.057 & 35 & 3.017 \\
8 & 34 & 0.393 & 34 & 0.927 & 38 & 1.262 & 36 & 3.255 \\
9 & 75 & 0.441 & 75 & 0.972 & 25 & 1.437 & 28 & 3.525 \\
10 & 37 & 0.484 & 24 & 0.974 & 33 & 1.472 & 20 & 4.066 \\
11 & 35 & 0.539 & 30 & 1.016 & 37 & 1.512 & 75 & 4.664 \\
12 & 30 & 0.849 & 35 & 1.021 & 32 & 1.671 & 37 & 5.581 \\
13 & 39 & 1.280 & 36 & 1.097 & 36 & 1.930 & 32 & 5.753 \\
14 & 33 & 1.661 & 39 & 1.125 & 75 & 2.046 & 38 & 6.477 \\
15 & 36 & 5.016 & 25 & 1.348 & 24 & 2.307 & 24 & 29.479 \\
\hline
\end{tabular}

Note: cc: Commodity Code; BCM: Box- Cox model

noted, if the mean of the observed data is to be taken as the predictor, ARV would be equal to unity. Even though it is claimed that the practical upper limit for ARV is one in the literature, ARV will be greater than unity if the average error is greater than the mean.

The second performance measure, SRMSE, is widely used in both spatial interaction modeling and the ANN literature. It is defined as:

$$
\text { SRMSE }=[1 / \bar{y}]\left[\sum_{i}^{n}\left(y_{i}-\hat{y}_{i}\right)^{2} / n\right]^{1 / 2}
$$

The standardized scores of this statistic allows the analyst to compare different categories of data. For this reason, it is especially useful for my purpose since I have 15 different groups of commodities with varying mean flows. SRMSE has a lower limit of zero and the upper limit varies depending on the distribution of the flows. When the average error is larger than the mean flow, the statistic takes values bigger than one [10].

The performance statistics for the 1997 predictions by both models are presented in Table $\mathrm{V}$ in ascending order. As an overall evaluation, it is possible to say that the Box-Cox model demonstrates a certain superiority for almost all commodity groups according to both evaluation measures.

The ARV for the Box-Cox model varies between 0.142 for food and kindred products (group 20) and 5.016 for machinery products 
(group 36) while it is between 0.607 for food and kindred products (groups 20) and 1.348 for furniture or fixture products (group 25) for the ANN Model. According to this statistic, only three commodity groups - primary metal (group 33), electrical machinery (group 36) and miscellaneous freight shipments (group 39) - have smaller ARVs for the ANN model than those of the Box-Cox model. For the rest of the product groups, the Box-Cox model has ARVs less than 0.6. However, the lowest bound of the ANN model ARV is 0.6. Thus according to the ARV measure, it is possible to state that, except for a few cases, the Box-Cox model outperforms the ANN Model.

The second measure, SRMSE, supports the above statement more strongly since the Box-Cox model has lower errors for all product groups, and its value is between 0.758 for the pulp and paper products (group 26) and 2.307 for the lumber and wood products (group 24). The ANN Model, however, has a lowest bound of 1.962 for the rubber and plastics products (group 30) and upper bound of 29.479 for lumber and wood products. The commodity group ordering pattern also does not display any discernable consistency. For example, a better performance commodity group according to one measure displays a poorer performance with respect to the other measure. (The predictions of the commodity groups for both models, with the best and worst performance according to both measures, are plotted across their observed values and can be found in the Appendix.)

\section{CONCLUSION}

The clearest finding of this study is that while a spatial interaction ANN model proves astonishing calibration superiority with respect to a conventional regression based Box-Cox model, the predictive performance of the same Box-Cox model out-performs that of the ANN model for interregional commodity flows. These results confirm the findings of earlier calibration studies [4,5] and prediction studies [2].

However, it should be noted that this result must not be taken as a final conclusion. There can be many reasonable analytical and empirical explanations for this difference in performance.

This result may stem from the stochastic nature of commodity flows. In modelling systems demonstrating more deterministic behaviour, ANN models imitate system behaviour better even if the functional relationships are not defined precisely. Examining the calibration results with the lower SRMSEs and higher $R^{2} \mathrm{~s}$ for the ANN model, it 
is possible to say that the error variances of the ANN model are smaller than those for the Box-Cox model. This also implies that the ANN is certainly a more efficient model. However, the stochastic part of the Box-Cox model, being substantially a statistical model, makes it a less biased model in forecasting commodity movement that is stochastic in nature. A similar argument may also be valid for the optimization models in predicting commodity flows. Even if optimization models have a very strong theoretical basis, the gravity model performs better in modelling commodity flows. Obviously, not having a sufficient degree of commodity disaggregation, the problem of back-hauling and the number of many different agents as shippers and receivers make freight movements highly stochastic. More stochastictype models may seem more suitable for modelling the spatial interaction of commodity flows at this point.

The type of architecture used in the ANN is a basic one: two-hidden layers using a back-propagation algorithm. This architecture was chosen by arbitrarily comparing the results of initial trials of different networks since the current state of the art in ANN specification does not have sufficiently robust evidence to advise the use of a preferred method. This situation may well imply that the different network architectures with different training algorithms could produce a better 'goodness of fit' for modelling commodity flows. Obviously, this is an important future research direction.

Finally, it should be noted that the Box-Cox and ANN models used in this study are unconstrained types of spatial interaction model. However, it is well-known that there are other types of spatial interaction models such as origin constrained, destination constrained and doubly constrained models. The literature on the specification of a constrained type of spatial neural network modelling has thus far been developing analytically [10]. However, the application and empirical performance of these constrained spatial neural models still remains a valid and open question, as well as a further example of the need for future research.

\section{References}

[1] Dougherty, M. (1995) 'A review of neural networks applied to transport', Transportation Research Part C 3(4), 247-260.

[2] Mozolin, M., Thill, J.C. and Usery, E.L. (2002) 'Trip distribution forecasting with multilayer perceptron neural networks: a critical evaluation', Transportation Research Part B 34, 53-73. 
[3] Celik, H.M. (2004) 'Modeling freight distribution using artificial neural networks', Transport Geography 12, 141-148.

[4] Black, W.R. (1995) 'Spatial interaction modeling using artificial neural networks', Transport Geography 3(3), 155-166.

[5] Fischer, M. and Gopal, S. (1994) 'Artificial neural networks: a new approach to modeling interregional telecommunication flows', Journal of Regional Science 34(4), 503-527.

[6] Fotheringham, A.S. and O'Kelly, M.E. (1989) Spatial Interaction Models: Formulation and Applications (Kluwer Academic Publishers, Dordrecht/Boston/London).

[7] Celik, H.M. and Guldmann, J.M. (2002) 'Spatial interaction modeling of interregional commodity flows', Paper presented at the 42nd European Congress of the Regional Science Association, Dortmund, Germany.

[8] Munakata, T. (1998) Fundamentals of the New Artificial Intelligence: Beyond Traditional Paradigms (Springer, New York).

[9] Hagan, M.T., Demuth, H.B. and Beale, M.H. (1996) Neural Network Design (Plus Publishing Co., Boston, MA).

[10] Fischer, M., Reismann, M. and Schindler, K.H. (2003) 'Neural network modeling of constrained spatial interaction flows: design, estimation and performance issues', Journal of Regional Science 43(1), 35-61. 
H. MURAT CELIK

定

氮

2

国

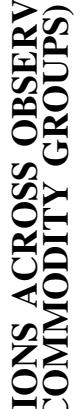

U日

동

ำ

芒
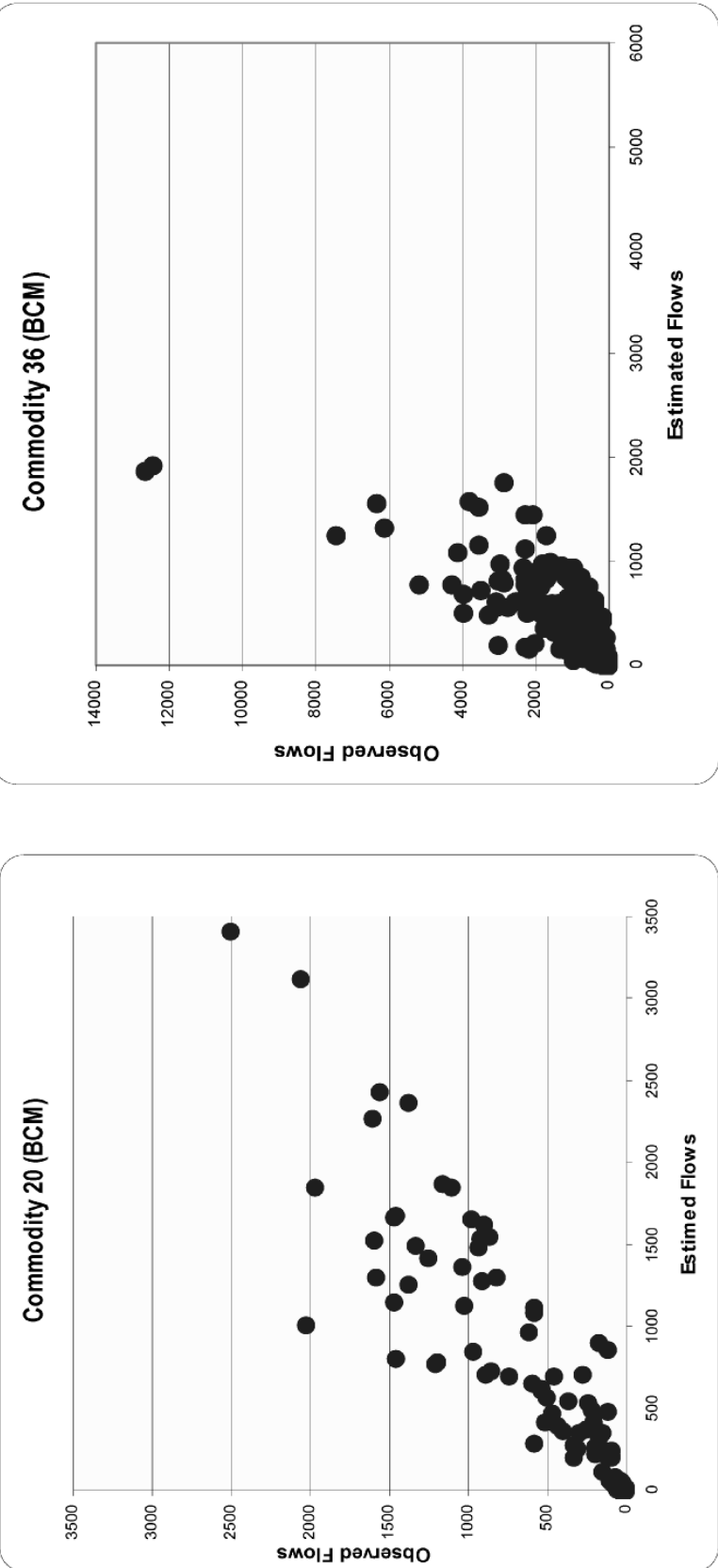
FORECASTING INTERREGIONAL COMMODITY FLOWS USING ANNS 465
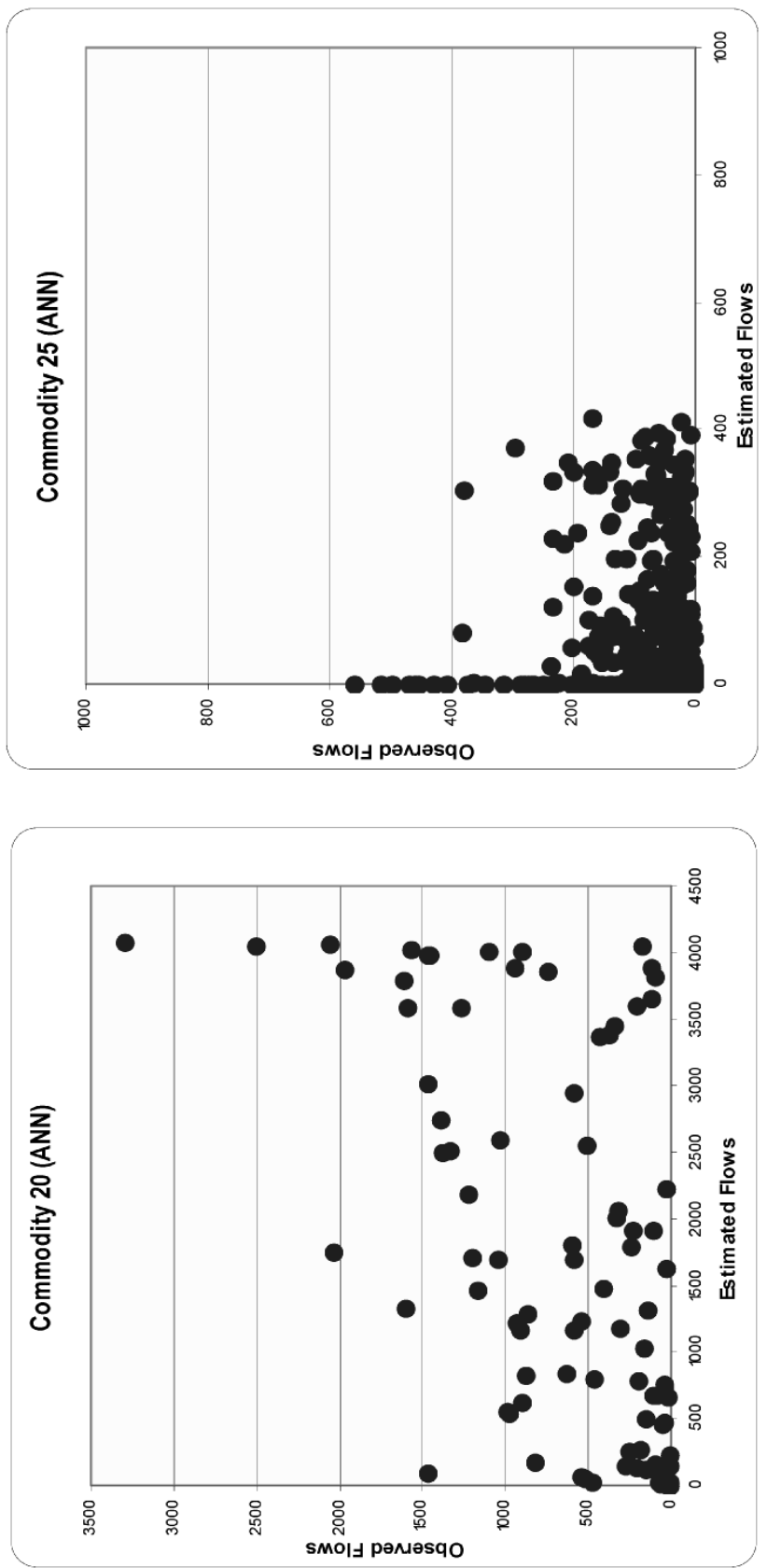

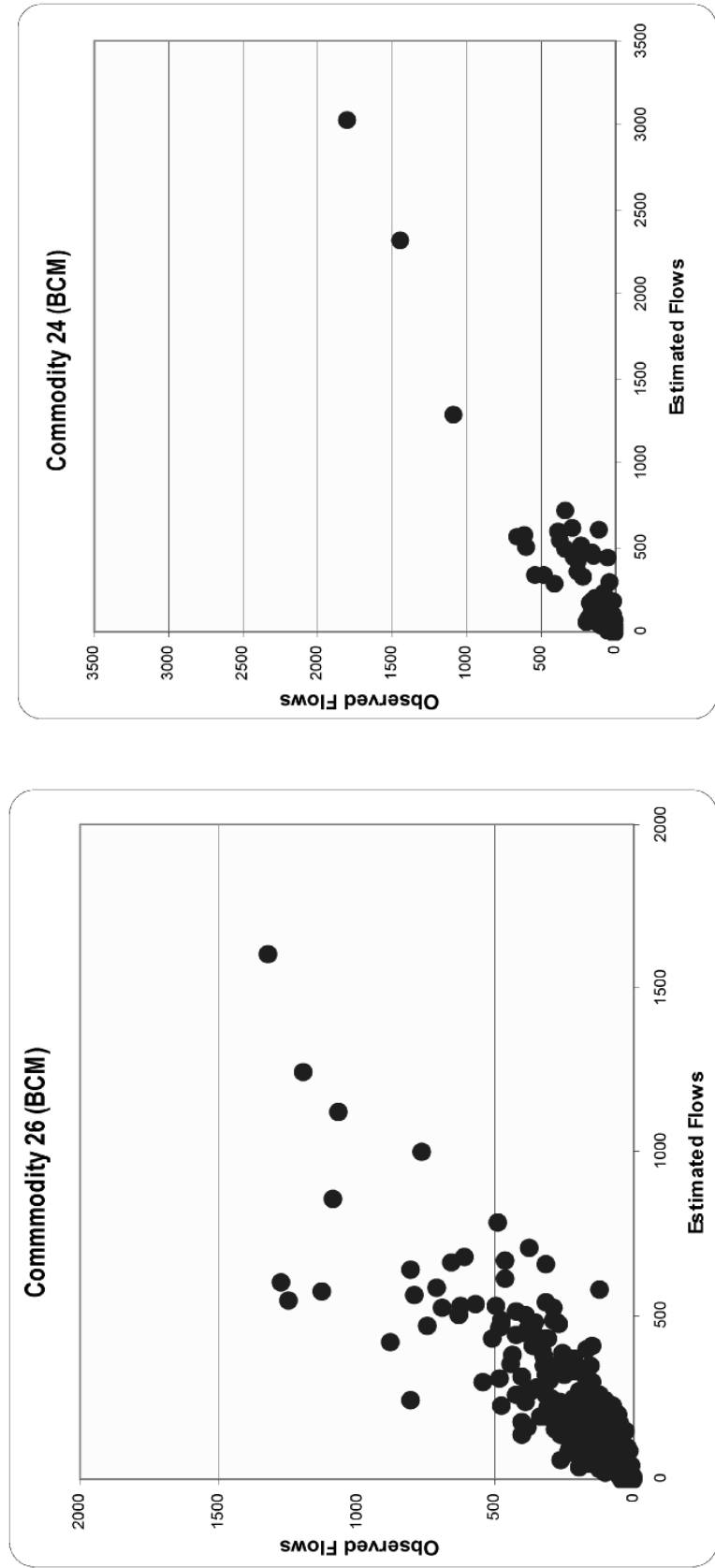
FORECASTING INTERREGIONAL COMMODITY FLOWS USING ANNS 467
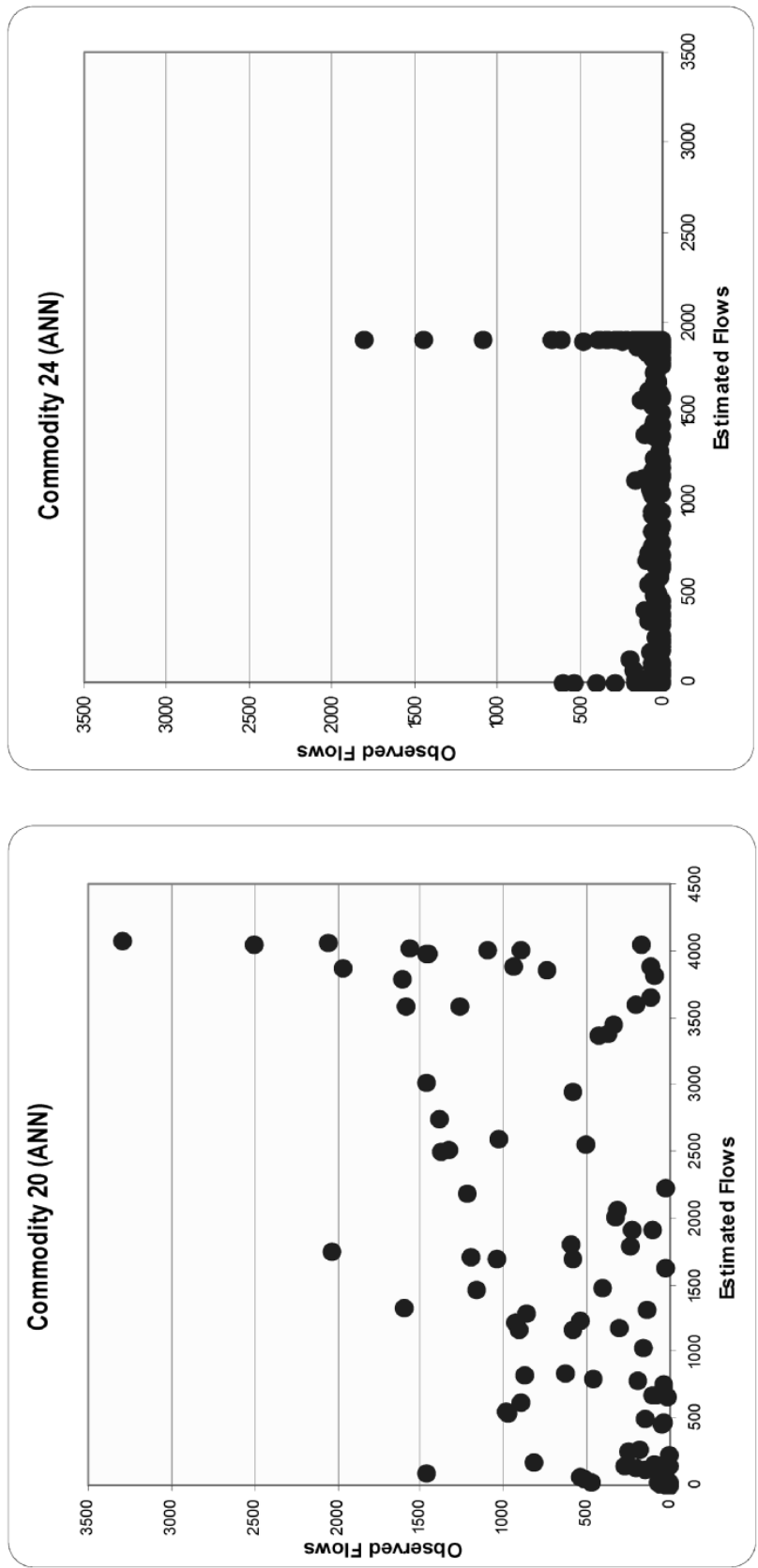
